\title{
Prevalence of and risk factors for anxiety and depression in Chinese patients with unruptured intracranial aneurysms treated by endovascular intervention
}

Xiao-Dong Zhai ${ }^{1,2}$, Jia-Xing Y Y ${ }^{1,2}$, Yong-Jie Ma ${ }^{1,2}$, Si-Shi Xiang ${ }^{1,2}$, Gui-Lin $\mathrm{Li}^{1,2}$, Chuan $\mathrm{He}^{1,2}$, Peng $\mathrm{Hu}^{1,2}$ and Hong-Qi Zhang ${ }^{1,2^{*}}$

\begin{abstract}
Background: Studies on anxiety and depression in unruptured intracranial aneurysm (UIA) patients after treatment via endovascular intervention are rare and controversial. We aimed to explore the prevalence of anxiety and depression among Chinese patients with UIAs treated by endovascular intervention and to identify which factors contribute to the development of these symptoms.

Methods: We performed a cross-sectional study on anxiety and depression in patients who underwent endovascular treatment for UIAs using the Hospital Anxiety and Depression Scale (HADS). The demographic, clinical and radiological data for all patients were retrospectively collected from the aneurysm database and medical records. Moreover, we utilized data from a large sample of 200 UIA patients and multivariate logistic regression analysis to investigate the risk factors for anxiety and depression in these patients. Candidate variables with $P$ values less than 0.20 in univariate analysis were included in the multivariate logistic regression analysis.

Results: Two hundred patients returned completed questionnaires in this study. Of these 200 patients, 34 (17.0\%) suffered from anxiety and 31 (15.5\%) suffered from depression $30.67 \pm 8.6$ months after being discharged. The multivariate analysis results indicated that shorter sleep times were statistically significantly associated with depression $(\mathrm{OR}=1.62,95 \% \mathrm{Cl}: 1.14 \sim 2.29, P=0.007$, Adjusted $P=0.02)$.

* Correspondence: xwzhanghq@163.com

'Department of Neurosurgery, Xuanwu Hospital, No. 45 Changchun Street,

Xicheng District, Beijing, China

${ }^{2}$ China International Neuroscience Institute (China-INI), Beijing, China

(c) The Author(s). 2020 Open Access This article is licensed under a Creative Commons Attribution 4.0 International License, which permits use, sharing, adaptation, distribution and reproduction in any medium or format, as long as you give appropriate credit to the original author(s) and the source, provide a link to the Creative Commons licence, and indicate if changes were made. The images or other third party material in this article are included in the article's Creative Commons licence, unless indicated otherwise in a credit line to the material. If material is not included in the article's Creative Commons licence and your intended use is not permitted by statutory regulation or exceeds the permitted use, you will need to obtain permission directly from the copyright holder. To view a copy of this licence, visit http://creativecommons.org/licenses/by/4.0/. The Creative Commons Public Domain Dedication waiver (http://creativecommons.org/publicdomain/zero/1.0/) applies to the data made available in this article, unless otherwise stated in a credit line to the data. 
(Continued from previous page)

Conclusion: The prevalences of anxiety and depression in UIA patients treated by endovascular intervention were 17.0 and $15.5 \%$, respectively. Shorter sleep times were significantly associated with depression. Our findings provide evidence for the clinical and psychological management of these patients.

Keywords: Unruptured intracranial aneurysms, Endovascular intervention, Anxiety, Depression, Prevalence, Risk factors

\section{Background}

Unruptured intracranial aneurysm (UIA) is a common disease with a prevalence of approximately $7 \%$ in Chinese adults aged 35 to 75 years [1]. In addition, advances in high-resolution imaging technologies and the increasing availability of these methods have led to a higher number of incidentally detected UIAs [1, 2]. Once an aneurysm ruptures, it typically causes subarachnoid hemorrhage (SAH) and sequelae, resulting in significant morbidity and mortality [3, 4]. Therefore, identifying and treating UIAs with a high propensity for rupture is critical for both neurosurgeons and neuroradiologists.

Evidence suggests that anxiety and depression symptoms are commonly associated with aneurysm disease, and both are important determinants of health-related quality of life in such patients $[5,6]$. The threat of rupture becomes the most obvious cause of preoperative anxiety and depression in patients with UIA $[5,7,8]$. In recent years, endovascular treatment has become a main strategy for treating for UIAs as a result of its superiority over microsurgery in both morbidity and mortality [9]. However, studies on anxiety and depression in UIA patients after treatment via endovascular intervention are rare and controversial $[5,10,11]$.

We aimed to explore the prevalence of anxiety and depression among Chinese UIA patients treated by endovascular intervention and to identify which factors contribute to the development of these symptoms.

\section{Methods}

\section{Study design and participants}

A cross-sectional study was performed. We retrospectively reviewed the hospital database for all consecutive UIA patients who underwent endovascular treatment in the Department of Neurosurgery, Xuanwu Hospital of Capital Medical University, from January 1, 2015, to May 31, 2017. The inclusion criteria were as follows: (1) diagnosed by digital subtraction angiography (DSA) and treated with endovascular intervention; and (2) aged 18 to 75 years. The exclusion criteria were as follows: (1) had traumatic, mycotic, bacterial, dissecting or fusiform aneurysms; (2) had a history of SAH or cerebral hemorrhage due to aneurysms or other causes; (3) died during the follow-up period; and (4) had a history of treatment for intracranial aneurysms (including microsurgical or endovascular treatment) or who underwent retreatment due to the incomplete obliteration before the follow-up. Ultimately, a total of 300 patients were included in this study.

\section{Assessment instrument}

The Hospital Anxiety and Depression Scale (HADS) is a promising tool for identifying and quantifying depression and anxiety symptoms in physically ill patients $[12,13]$. Therefore, the HADS was used to assess anxiety and depression symptoms in UIA patients. The HADS is composed of seven items related to anxiety symptoms and seven related to depression symptoms, for 14 items in total $[13,14]$. All 14 items were answered by the patients using a four-point Likert scale, with the aim to assess their subjective experience with anxiety and depression symptoms. In this study, anxiety and depression were dichotomized based on the recommended threshold (equal to or above 8 points), with a sensitivity and specificity in the range of 0.70 to 0.90 [15]. The content of the questionnaire was mainly composed of the HADS, which aimed to assesses participation in the presence of depressive and anxiety symptoms, for the previous 4 weeks. In addition, the questionnaire includes important items such as average daily sleep time, educational level, ratio of treatment costs to annual household income and physical exercise level within the last month. A combined online questionnaire was sent to the patients who were willing to respond.

\section{Data collection}

We conducted a telephone follow-up of the 300 patients who met the inclusion and exclusion criteria; of these patients, 270 were successfully followed up, for a followup rate of $90.0 \%$. We sent the combined online questionnaire to 228 patients who were willing to respond. If we received no response 7 days after sending the first online questionnaire, we sent another copy of the same online questionnaire to the patient, and the deadline for receiving the completed questionnaire was 2 weeks after the first attempt. Eventually, 200 patients returned a completed questionnaire within the set time, accounting for $66.7 \%$ of all 300 UIA patients. The demographic, clinical and radiological data for all patients were retrospectively collected from the aneurysm database and 
medical records. The duration since treatment was defined as the time from treatment to the follow-up. A good neurological outcome was defined as a modified Rankin Scale (mRS) score of 2 or less. In addition, mRS progression at discharge was defined as an increase in the mRS score at the time of discharge compared to the preoperative score. Due to the high representativeness, the ratio of treatment costs to annual household income is recommended as an evaluation of the treatmentrelated financial burden affecting symptoms of anxiety and depression. Radiological follow-up examinations included magnetic resonance angiography (MRA), computed tomography angiography (CTA) or DSA.

\section{Statistical methods}

Categorical variables were compared between the 2 groups using the Pearson $\chi^{2}$ test, continuity correction, and Fisher's exact 2-tailed test. Continuous variables were compared between groups using Student's t-test. Interval data are reported as the mean \pm standard deviation, and nominal data are expressed as absolute numbers and valid percentages. Data were tested for normality by making P-P and Q-Q plots. A multivariate logistic regression analysis was used to identify the association of the described variables with anxiety and depression in patients. Candidate variables with $P$ values less than 0.20 in univariate analysis were included in the multivariate logistic regression analysis. Statistical significance was defined as $P<0.05$. To account for the multiple testing, the $P$-values were corrected by false

Table 1 Demographic characteristics of UIAs patients

\begin{tabular}{|c|c|c|}
\hline \multicolumn{2}{|l|}{ Characteristics } & Value $(n, \%)$ \\
\hline \multicolumn{2}{|l|}{ Age,years,mean \pm SD } & $55.2 \pm 9.48$ \\
\hline \multicolumn{2}{|l|}{ Gender (Female) } & $117(58.5 \%)$ \\
\hline \multicolumn{2}{|l|}{ Hypertension } & $108(54.0 \%)$ \\
\hline \multicolumn{2}{|l|}{ Diabetes } & $17(8.5 \%)$ \\
\hline \multicolumn{2}{|l|}{ Heart disease } & $25(12.5 \%)$ \\
\hline \multicolumn{2}{|l|}{${ }^{1}$ ICVD history } & $37(18.5)$ \\
\hline \multicolumn{2}{|l|}{ Smoking } & $23(11.5 \%)$ \\
\hline \multirow[t]{2}{*}{ Physical exercise } & At least once a week & $140(70.0 \%)$ \\
\hline & 0 time a week & $60(30.0 \%)$ \\
\hline \multicolumn{2}{|l|}{ Sleep time } & $6.88 \pm 1.19$ \\
\hline \multirow[t]{2}{*}{ Education level, years } & $\leq 12$ & $131(65.5 \%)$ \\
\hline & $>12$ & 69 (34.5\%) \\
\hline \multicolumn{2}{|l|}{ Anxiety } & $34(17.0 \%)$ \\
\hline \multicolumn{2}{|l|}{ Depression } & 31 (15.5\%) \\
\hline \multirow[t]{2}{*}{${ }^{2}$ Ratio } & $0-100 \%$ & $133(66.5 \%)$ \\
\hline & $>100 \%$ & 67 (33.5\%) \\
\hline
\end{tabular}

${ }^{1}$ ICVD represents "Ischemic cerebrovascular disease", ${ }^{2}$ Ratio represents "Ratio of treatment cost to annual household income"
Table 2 Clinical and radiological characteristics of UIA patients

\begin{tabular}{lll}
\hline Characteristics & & Value(n, \%) \\
\hline Diagnosis to treatment time & $0-3$ months & $158(79.0 \%)$ \\
& $>3$ months & $42(21.0 \%)$ \\
Intervention materials & Simple coiling & $40(20.0 \%)$ \\
& Stent or ${ }^{1} \mathrm{FD}$ & $160(80.0 \%)$ \\
mRS progression at discharge & No & $190(95.0 \%)$ \\
& Yes & $10(5.0 \%)$ \\
Treatment-related complications & & $8(4.0 \%)$ \\
Duration since treatment & $\leq 30$ months & $101(50.5 \%)$ \\
& $>30$ months & $99(49.5 \%)$ \\
Incomplete obliteration & & $7 / 167(4.19 \%)$ \\
Multiple aneurysms & & $39(19.5 \%)$ \\
Location & Anterior circulation & $163(81.5 \%)$ \\
& Posterior circulation & $32(16.0 \%)$ \\
& Both & $5(2.5 \%)$ \\
\hline
\end{tabular}

${ }^{1}$ FD represents "Flow diversion"

discovery rate (FDR). Statistical analysis was performed using SPSS Statistics version 24.0 software (IBM Corp., Armonk, New York, USA).

\section{Results}

Demographic, clinical and radiological characteristics

Two hundred patients returned completed questionnaires. All patient information is shown in Table 1 and Table 2. Of the 200 patients, 117 were female, and 83 were male; their mean age was $55.2 \pm 9.48$ years (range 23-74 years). They had a total of 245 aneurysms (161 patients had one aneurysm, 34 had two, 4 had three, and one had four), and the majority of aneurysms occurred in the anterior circulation (81.5\%) (Table 2). A total of $160(80 \%)$ patients underwent stenting or flow diversion (FD), and 40 patients (20\%) underwent simple coiling. No technical failures were observed in our cohort, and 8 patients experienced postoperative ischemia-related complications. Among them, one patient with severe postoperative ischemic complications had an mRS of 5 at discharge, and the other patients exhibited good postoperative neurological outcomes $(\mathrm{mRS}=0-2)$. All patients presented with good neurological outcomes $(\mathrm{mRS}=0-2)$ at follow-up. Ten patients (5\%) showed mRS progression at discharge compared with the preoperative mRS score. For all 200 patients, the duration since treatment ranged between 18 and 45 months, with an average of $30.67 \pm 8.6$ months. Radiological follow-up was available for 167 patients, with a mean follow-up period of $30.76 \pm 8.43$ months; 7 patients experienced incomplete obliteration and had not received further treatment at follow-up. 
Table 3 Univariate analysis of the anxiety and depression in UIA patients

\begin{tabular}{|c|c|c|c|c|c|c|}
\hline Variables & Anxiety & non-Anxiety & $P$-value & Deperssion & non-Depression & $P$-value \\
\hline Age,years,mean $\pm S D$ & $54.9 \pm 8.88$ & $55.25 \pm 9.62$ & 0.86 & $55.26 \pm 9.40$ & $55.19 \pm 9.52$ & 0.97 \\
\hline Gender (male) & $16(47.1 \%)$ & 67 (40.4\%) & 0.47 & 9 (29.0\%) & $74(43.8 \%)$ & 0.13 \\
\hline Hypertension & $23(67.6 \%)$ & $85(51.2 \%)$ & 0.08 & 19 (61.3\%) & 89 (52.7\%) & 0.44 \\
\hline Diabetes & $3(8.8 \%)$ & $14(8.4 \%)$ & 0.99 & $3(9.7 \%)$ & $14(8.3 \%)$ & 0.99 \\
\hline Heart disease & $4(11.8 \%)$ & $21(12.7 \%)$ & 0.99 & $3(9.7 \%)$ & $22(13 . .0 \%)$ & 0.83 \\
\hline${ }^{1}$ ICVD history & $9(26.5 \%)$ & $28(16.9 \%)$ & 0.19 & $7(22.6 \%)$ & $30(17.8 \%)$ & 0.52 \\
\hline Smoking & $5(14.7 \%)$ & $18(10.8 \%)$ & 0.73 & $3(9.7 \%)$ & $20(11.8 \%)$ & 0.97 \\
\hline Physical exercise & $23(67.6 \%)$ & $117(70.5 \%)$ & 0.74 & 19 (61.3\%) & $121(71.6 \%)$ & 0.25 \\
\hline Sleep time & $6.53 \pm 1.21$ & $6.95 \pm 1.18$ & 0.06 & $6.29 \pm 1.22$ & $6.99 \pm 1.16$ & 0.003 \\
\hline Education level, years $\leq 12$ years & $26(76.5 \%)$ & $105(63.3 \%)$ & 0.14 & $22(71.0 \%)$ & $109(64.5 \%)$ & 0.49 \\
\hline${ }^{2}$ Ratio $>100 \%$ & $17(50.0 \%)$ & $50(30.1 \%)$ & 0.03 & $14(45.2 \%)$ & $53(31.4 \%)$ & 0.14 \\
\hline Diagnosis to treatment time $\leq 3$ months & $27(79.4 \%)$ & $131(78.9 \%)$ & 0.99 & $25(80.6 \%)$ & $133(78.7 \%)$ & 0.82 \\
\hline $\mathrm{mRS}$ progression at discharge & $3(8.8 \%)$ & $7(4.2 \%)$ & 0.49 & $3(9.7 \%)$ & $7(4.1 \%)$ & 0.39 \\
\hline Intervention materials (Stent or ${ }^{3} \mathrm{FD}$ ) & $29(85.3 \%)$ & $131(78.9 \%)$ & 0.40 & $26(83.9 \%)$ & $134(79.3 \%)$ & 0.56 \\
\hline Treatment-related complications & $3(8.8 \%)$ & $5(3.0 \%)$ & 0.27 & $1(3.2 \%)$ & $7(4.1 \%)$ & 0.99 \\
\hline Duration since treatment & $31.50 \pm 7.82$ & $30.49 \pm 8.77$ & 0.54 & $30.06 \pm 8.06$ & $30.78 \pm 8.72$ & 0.67 \\
\hline Incomplete obliteration & $2(6.7 \%)$ & $5(3.6 \%)$ & 0.81 & $2(7.7 \%)$ & $5(3.5 \%)$ & 0.66 \\
\hline Multiple aneurysms & $7(20.6 \%)$ & $32(19.3 \%)$ & 0.99 & $8(25.8 \%)$ & $31(18.3 \%)$ & 0.34 \\
\hline Remain untreated aneurysm & $1(2.9 \%)$ & $9(5.4 \%)$ & 0.86 & $1(3.2 \%)$ & $9(5.3 \%)$ & 0.96 \\
\hline Location & & & 0.04 & & & 0.32 \\
\hline Anterior circulation & $23(67.6 \%)$ & $140(84.3 \%)$ & & $24(77.4 \%)$ & $139(82.2 \%)$ & \\
\hline Posterior circulation & $9(26.5 \%)$ & $23(13.9 \%)$ & & $5(16.1 \%)$ & $27(16.0 \%)$ & \\
\hline Both & $2(5.9 \%)$ & $3(1.8 \%)$ & & $2(6.5 \%)$ & $3(1.8 \%)$ & \\
\hline
\end{tabular}

${ }^{1} \mathrm{ICVD}$ represents "Ischemic cerebrovascular disease", ${ }^{2}$ Ratio represents "Ratio of treatment cost to annual household income" ${ }^{3} \mathrm{FD}$ represents "Flow diversion"

Table 4 Multivariable analysis of the anxiety and depression in UIA patients

\begin{tabular}{|c|c|c|c|c|}
\hline & Variables & OR $(95 \% \mathrm{Cl})$ & $P$-value & Adjusted $P$-value \\
\hline \multirow[t]{9}{*}{ Anxiety } & Hypertension & $1.99(0.86 \sim 4.61)$ & 0.11 & 0.19 \\
\hline & ${ }^{1}$ ICVD history & $2.03(0.77 \sim 5.30)$ & 0.15 & 0.21 \\
\hline & Education level, years $\leq 12$ years & $1.34(0.54 \sim 3.35)$ & 0.53 & 0.53 \\
\hline & ${ }^{2}$ Ratio > 100\% & $2.42(1.08 \sim 5.41)$ & 0.03 & 0.11 \\
\hline & Sleep time & $1.51(1.06 \sim 2.14)$ & 0.02 & 0.14 \\
\hline & Location & & & \\
\hline & Anterior circulation & 1 & & \\
\hline & Posterior circulation & $2.21(0.85 \sim 5.71)$ & 0.10 & 0.23 \\
\hline & Both & $3.50(0.43 \sim 28.49)$ & 0.24 & 0.28 \\
\hline \multirow[t]{3}{*}{ Depression } & Gender (Female) & $1.51(0.64 \sim 3.59)$ & 0.35 & 0.35 \\
\hline & Sleep time & $1.62(1.14 \sim 2.29)$ & 0.007 & 0.02 \\
\hline & ${ }^{2}$ Ratio > 100\% & $1.80(0.80 \sim 4.03)$ & 0.15 & 0.23 \\
\hline
\end{tabular}

IICVD represents "Ischemic cerebrovascular disease", 2Ratio represents "Ratio of treatment cost to annual household income" 
Prevalence and risk factors of anxiety and depression As shown in Table 2, of the 200 UIA patients, 34 (17.0\%) suffered from anxiety and 31 (15.5\%) suffered from depression $30.67 \pm 8.6$ months after being discharged. Table 3 summarizes the univariate analysis of the determinants of anxiety and depression. The independent variables with $P$ values less than 0.20 in the univariate analysis were included in the multivariate logistic regression analysis. Therefore, anxiety-related variables, including education level, hypertension, ischemic cerebrovascular disease history, location of aneurysm, sleep time and ratio of treatment costs to annual household income, were included; depression-related variables, including gender, sleep time, and ratio of treatment costs to annual household income, were included. Table 4 presents the explanatory variables that were significantly associated with anxiety and depression. The multivariate analysis results indicated that shorter sleep times were statistically significantly associated with depression $(\mathrm{OR}=1.62,95 \%$ CI: $1.14 \sim 2.29, P=0.007$, Adjusted $P=$ 0.02). Treatment cost exceeding the annual household income $(\mathrm{OR}=2.42,95 \% \mathrm{CI}: 1.08 \sim 5.41, P=0.03)$ and shorter sleep times $(\mathrm{OR}=1.51,95 \% \mathrm{CI}: 1.06 \sim 2.14, \mathrm{P}=$ 0.02 ) were significantly associated with anxiety, however, this association was not statistically significant after FDR correction $(P=0.11$ and 0.14 , respectively).

\section{Discussion}

A pattern of significant psychological impairment was found to be associated with an identified but untreated UIA [5, 16, 17]. For example, Towgood K et al. [16] reported that $36 \%$ of untreated UIA patients presented with a pattern of significant psychosocial impairment 6 months post-treatment. Su SH et al. [5] reported that $84 \%$ of patients were found to have mild to severe anxiety 1 year after discovering the UIA. In addition, even 5 years after the detection of an UIA, 39\% of patients were mildly to severely depressed, and $32 \%$ of patients had mild to severe anxiety. After an aneurysm is detected, many patients presented with complex psychological changes due to confusion regarding disease-related knowledge and sudden changes in their physical roles and physical functions, thus causing anxiety or depression symptoms.

Studies reported that patients with a longer duration since treatment typically showed lower anxiety and depression levels than those with a shorter duration since treatment $[5,10]$. This phenomenon indicated that patients may still feel anxiety or depression for a short period of time after treatment because they fear bleeding or recurrence of the aneurysm, but these symptoms improve over time. Nevertheless, in this study, there was no significant difference in the incidence of anxiety and depression between the two groups stratified by the median duration since treatment (30 months), which may suggest that the anxiety and depression of these patients did not significantly decrease over time. In addition, several studies have suggested that a considerable number of UIA patients who undergo microsurgery or endovascular treatment suffer from anxiety or depression. For example, Li Y et al. [10] reported that $18.2 \%$ $(n=8)$ and $27.3 \%(n=12)$ of the clipping group had anxiety and depression, respectively, and $17.6 \%(n=13)$ and $24.3 \%(n=18)$ of the coiling group had anxiety and depression, respectively. Solheim et al. [11] reported that $26.9 \%(n=7)$ and $19.2 \%(n=5)$ of the open surgery group suffered from anxiety and depression, respectively, and $31.6 \%(n=6)$ and $10.5 \%(n=2)$ of the endovascular coiling group suffered from anxiety and depression, respectively. Unfortunately, the results of these studies are limited by many factors, such as small sample sizes, different assessment instruments and patient cooperation.

Currently, endovascular treatment is considered a first-line strategy for UIAs because of its superiority to microsurgical clipping in terms of both morbidity and mortality $[9,18]$. However, studies on anxiety and depression in UIA patients treated with endovascular intervention are rare and controversial. In addition, the risk factors for anxiety and depression in these patients need to be identified. This large cross-sectional study took place over an average period of $30.67 \pm 8.6$ months and assessed the anxiety and depression outcomes in UIA patients who underwent endovascular treatment. In our study, we found that $34(17.0 \%)$ patients suffered from anxiety, and 31 (15.5\%) suffered from depression, meaning that a certain number of patients were still in a state of psychological impairment after an average recovery period of $30.67 \pm 8.6$ months. The multivariate analysis results indicated that shorter sleep times were significantly associated with anxiety and depression. Thus, we recommend that patients should ensure adequate sleep and a healthy lifestyle. Treatment costs exceeding the annual household income and shorter sleep times was significantly associated with anxiety, although this was not statistically significant after FDR correction for $P$ values. Excessive financial burden tends create a state of anxiety. Therefore, corresponding policies and measures should be implemented to relieve the financial burden on these patients.

The main limitation of this study was its retrospective design. The anxiety and depression of these patients was not assessed before treatment, so it is not possible to compare anxiety and depression before and after treatment. Although our follow-up rate $(90.0 \%)$ and questionnaire response rate $(74.1 \%)$ are high and impressive, we still cannot ignore the existence of selection bias. In addition, the HADS is widely used for patients to provide a subjective assessment of depressive and anxiety 
symptomatology rather than as a standardized criterion for the diagnosis of clinical depression and anxiety, which may result in false-positive results. It is necessary to conduct a prospective and multicenter study in the future.

\section{Conclusion}

Our current findings demonstrated that the prevalences of anxiety and depression in UIA patients treated with endovascular intervention were 17.0 and $15.5 \%$, respectively. Shorter sleep times were significantly associated with depression. Our findings provide evidence for the clinical and psychological management of these patients.

\section{Abbreviations}

UIA: Unruptured intracranial aneurysm; HADS: Hospital Anxiety and Depression Scale; SAH: Subarachnoid hemorrhage; DSA: Digital subtraction angiography; MRA: Magnetic resonance angiography; CTA: Computed tomography angiography; mRS: Modified Rankin Scale

\section{Acknowledgements}

We want to thank all the patients for their participation in this research.

\section{Authors' contributions}

ZX and ZH designed questionnaires and study protocol, analysis of data, and write up of article. MY, YJ, LG, HC and HP analyzed data and contributed in write-up of the different sections of the manuscript. XS and ZX contributed in data analysis. All authors read and approved the final manuscript.

\section{Funding}

This work was supported by the National Key R\&D program of China with grant 2016 YFC1300800 and the Beijing Municipal Administration of Hospitals' Ascent Plan with grant DFL20180801. The funders had no role in study design, data collection and analysis, decision to publish, or preparation of the manuscript.

\section{Availability of data and materials}

The datasets used and/or analyzed during the current study are available from the corresponding author on reasonable requests.

\section{Ethics approval and consent to participate}

Participants indicated their agreement to participate in the study via the electronic informed consent included in the survey form. The ethic approval for this study was issued by the Institutional Review Board of the Xuanwu Hospital of Capital Medical University (Xuanwu Hospital, No.2017082).

\section{Consent for publication}

Not applicable.

\section{Competing interests}

The authors declare that they have no competing interests.

Received: 2 February 2020 Accepted: 24 August 2020

Published online: 03 September 2020

\section{References}

1. Li MH, Chen SW, Li YD, Chen YC, Cheng YS, Hu DJ, Tan HQ, Wu Q, Wang W, Sun ZK, et al. Prevalence of unruptured cerebral aneurysms in Chinese adults aged 35 to 75 years: a cross-sectional study. Ann Intern Med. 2013; 159(8):514-21.

2. Vlak MH, Algra A, Brandenburg R, Rinkel GJ. Prevalence of unruptured intracranial aneurysms, with emphasis on sex, age, comorbidity, country, and time period: a systematic review and meta-analysis. Lancet Neurol. 2011;10(7):626-36.

3. Gross BA, Lai PM, Du R. Impact of aneurysm location on hemorrhage risk. Clin Neurol Neurosurg. 2014;123:78-82.
4. Weir B, Disney L, Karrison T. Sizes of ruptured and unruptured aneurysms in relation to their sites and the ages of patients. J Neurosurg. 2002;96(1):64-70.

5. Su SH, Xu W, Hai J, Yu F, Wu YF, Liu YG, Zhang L. Cognitive function, depression, anxiety and quality of life in Chinese patients with untreated unruptured intracranial aneurysms. J Clin Neurosci. 2014;21(10):1734-9.

6. Ngasa SN, Sama CB, Dzekem BS, Nforchu KN, Tindong M, Aroke D, Dimala CA. Prevalence and factors associated with depression among medical students in Cameroon: a cross-sectional study. BMC Psychiatry. 2017;17(1):216.

7. Haug T, Sorteberg A, Sorteberg W, Lindegaard KF, Lundar T, Finset A. Surgical repair of unruptured and ruptured middle cerebral artery aneurysms: impact on cognitive functioning and health-related quality of life. Neurosurgery. 2009;64(3):412-20 discussion 421-412.

8. Buijs JE, Greebe P, Rinkel GJ. Quality of life, anxiety, and depression in patients with an unruptured intracranial aneurysm with or without aneurysm occlusion. Neurosurgery. 2012;70(4):868-72.

9. Zhao J, Lin H, Summers R, Yang M, Cousins BG, Tsui J. Current treatment strategies for intracranial aneurysms: an overview. Angiology. 2018;69(1):17-30

10. Li Y, Dai W, Zhang J. Anxiety, depression and quality of life in patients with a treated or untreated unruptured intracranial aneurysm. J Clin Neurosci. 2017:45:223-6.

11. Solheim O, Eloqayli $H$, Muller TB, Unsgaard G. Quality of life after treatment for incidental, unruptured intracranial aneurysms. Acta Neurochir. 2006; 148(8):821-30 discussion 830.

12. Zigmond AS, Snaith RP. The hospital anxiety and depression scale. Acta Psychiatr Scand. 1983;67(6):361-70.

13. Thombs BD, Benedetti A, Kloda LA, Levis B, Azar M, Riehm KE, Saadat N, Cuijpers P, Gilbody S, loannidis JP, et al. Diagnostic accuracy of the depression subscale of the hospital anxiety and depression scale (HADS-D) for detecting major depression: protocol for a systematic review and individual patient data meta-analyses. BMJ Open. 2016;6(4):e011913.

14. Botega NJ, Bio MR, Zomignani MA, Garcia C Jr, Pereira WA. Mood disorders among inpatients in ambulatory and validation of the anxiety and depression scale HAD. Revista de saude publica. 1995;29(5):355-63.

15. Bjelland I, Dahl AA, Haug TT, Neckelmann D. The validity of the hospital anxiety and depression scale. An updated literature review. J Psychosom Res. 2002;52(2):69-77.

16. Towgood K, Ogden JA, Mee E. Psychosocial effects of harboring an untreated unruptured intracranial aneurysm. Neurosurgery. 2005;57(5):858-6 discussion 858-856.

17. van der Schaaf IC, Brilstra EH, Rinkel GJ, Bossuyt PM, van Gijn J. Quality of life, anxiety, and depression in patients with an untreated intracranial aneurysm or arteriovenous malformation. Stroke. 2002;33(2):440-3.

18. Thompson BG, Brown RD Jr, Amin-Hanjani S, Broderick JP, Cockroft KM, Connolly ES Jr, Duckwiler GR, Harris CC, Howard VJ, Johnston SC, et al. Guidelines for the Management of Patients with Unruptured Intracranial Aneurysms: a guideline for healthcare professionals from the American Heart Association/American Stroke Association. Stroke. 2015;46(8):2368-400.

\section{Publisher's Note}

Springer Nature remains neutral with regard to jurisdictional claims in published maps and institutional affiliations.
Ready to submit your research? Choose BMC and benefit from:
- fast, convenient online submission
- thorough peer review by experienced researchers in your field
- rapid publication on acceptance
- support for research data, including large and complex data types
- gold Open Access which fosters wider collaboration and increased citations
- maximum visibility for your research: over $100 \mathrm{M}$ website views per year
At BMC, research is always in progress.
Learn more biomedcentral.com/submissions 